Tim Sinnecker, MD

Sophie Schumacher

Katharina Mueller, MD

Florence Pache, MD

Petr Dusek, MD

Lutz Harms, MD

Klemens Ruprecht, MD

Petra Nytrova, MD

Sanjeev Chawla, MD

Thoralf Niendorf, $\mathrm{PhD}$

Ilya Kister, MD

Friedemann Paul, MD

Yulin Ge, MD

Jens Wuerfel, MD

Correspondence to

Dr. Paul:

friedemann.paul@charite.de

\title{
MRI phase changes in multiple sclerosis vs neuromyelitis optica lesions at $7 \mathrm{~T}$
}

OPEN

\section{ABSTRACT}

Objective: To characterize paramagnetic MRI phase signal abnormalities in neuromyelitis optica spectrum disorder (NMOSD) vs multiple sclerosis (MS) lesions in a cross-sectional study.

Methods: Ten patients with NMOSD and 10 patients with relapsing-remitting MS underwent 7-tesla brain MRI including supratentorial T2*-weighted imaging and supratentorial susceptibility weighted imaging. Next, we analyzed intra- and perilesional paramagnetic phase changes on susceptibility weighted imaging filtered magnetic resonance phase images.

Results: We frequently observed paramagnetic rim-like (75 of 232 lesions, 32\%) or nodular (32 of 232 lesions, 14\%) phase changes in MS lesions, but only rarely in NMOSD lesions (rim-like phase changes: 2 of 112 lesions, 2\%, $p<0.001$; nodular phase changes: 2 of 112 lesions, $2 \%, p<0.001$ ).

Conclusions: Rim-like or nodular paramagnetic MRI phase changes are characteristic for MS lesions and not frequently detectable in NMOSD. Future prospective studies should ask whether these imaging findings can be used as a biomarker to distinguish between NMOSD- and MS-related brain lesions. Neurol Neuroimmunol Neuroinflamm 2016;3:e259; doi: 10.1212/NXI.0000000000000259

\section{GLOSSARY}

ICC $=$ intraclass correlation; $\mathbf{M S}=$ multiple sclerosis; NMOSD $=$ neuromyelitis optica spectrum disorder; $\mathbf{S W I}=$ susceptibility weighted imaging; T2*w $=$ T2*-weighted.

Neuromyelitis optica spectrum disorders (NMOSD) and multiple sclerosis (MS) are distinct autoimmune CNS diseases with sometimes overlapping clinical phenotypes. ${ }^{1}$ Since treatment options for these 2 CNS diseases differ considerably, ${ }^{1}$ the distinction between NMOSD and MS is of high clinical relevance. Recently, new international consensus diagnostic criteria were proposed for NMOSD emphasizing the role of MRI and aquaporin-4 immunoglobulin G antibody testing. ${ }^{2}$ Notwithstanding this success, the distinction of NMOSD vs MS can still be challenging in current clinical practice. Ultra-high field MRI at 7 tesla (T) has improved the detection and morphologic characterization of brain lesions by visualizing a central intralesional vein and a T2*-weighted $(\mathrm{T} 2 * \mathrm{w})$ hypointense rim around many MS lesions. ${ }^{3,4}$ Contrarily, these imaging features are only rarely depictable in NMOSD lesions. ${ }^{3,4}$ At $3 \mathrm{~T}$, susceptibility-induced MRI phase signal changes were reported to be specific for MS in contrast to other neurologic disorders such as migraine, antiphospholipid syndrome, and Parkinson disease. ${ }^{5}$ Inspired by these findings, we rescanned previously reported patients with NMOSD at $7 \mathrm{~T}^{3}$ and included additional NMOSD cases to describe MRI phase signal changes in NMOSD vs MS lesions in a cross-sectional study.

\footnotetext{
From the NeuroCure Clinical Research Center (T.S., S.S., K.M., F. Pache, F. Paul, J.W.), Clinical and Experimental Multiple Sclerosis Research Center (L.H., K.R., F. Paul), and Department of Neurology (L.H., K.R., F. Paul), Charité-Universitaetsmedizin Berlin; Institute of Neuroradiology (P.D., J.W.), Universitaetsmedizin Goettingen, Germany; Department of Neurology and Center of Clinical Neuroscience (P.D., P.N.), Charles University in Prague, 1st Faculty of Medicine and General University Hospital in Prague, Czech Republic; Berlin Ultrahigh Field Facility (T.N., J.W.), Max Delbrueck Center for Molecular Medicine, Berlin; Experimental and Clinical Research Center (T.N., F. Paul, J.W.), CharitéUniversitaetsmedizin Berlin and Max Delbrueck Center for Molecular Medicine, Berlin, Germany; Department of Radiology (S.C., Y.G.), and Multiple Sclerosis Care Center, Department of Neurology (I.K.), NYU School of Medicine, New York, NY; and Medical Imaging Analysis Center AG (T.S., J.W.), Basel, Switzerland. T.S. is currently with Universitätsspital Basel, Switzerland.

Funding information and disclosures are provided at the end of the article. Go to Neurology.org/nn for full disclosure forms. The Article Processing Charge was paid by the authors.

This is an open access article distributed under the terms of the Creative Commons Attribution-NonCommercial-NoDerivatives License 4.0 (CC BY-NC-ND), which permits downloading and sharing the work provided it is properly cited. The work cannot be changed in any way or used commercially.
} 
METHODS Study participants. Ten patients with NMOSD underwent ultra-high field MRI at 7T. Inclusion criteria were diagnosis of NMOSD as defined by the current international consensus diagnostic criteria for $\mathrm{NMOSD},{ }^{2}$ age of at least 18 years, and no contraindications to $7 \mathrm{~T}$ MRI. Four of these patients have been previously reported in a 7T MRI study on $\mathrm{T} 2{ }^{*} \mathrm{w}$ lesion morphology ${ }^{3}$ and were rescanned. Nine patients with NMOSD were seropositive for aquaporin-4 immunoglobulin G. Ten patients with relapsing-remitting MS as defined by the current panel criteria ${ }^{6}$ were selected from a research database of the NeuroCure Clinical Research Center as controls. More details are presented in table 1.

The study was approved by the local ethics committee (EA 1/ 054/09). Written consent was obtained from all participants before examination.

MRI acquisition. Ultra-high field MRIs were acquired using a 7T Siemens whole body scanner (Magnetom; Siemens, Erlangen, Germany) by applying a 24-channel receive head coil (Nova Medical, Wilmington, MA) equipped with a birdcage volume coil used for transmission. The imaging protocol included supratentorial 2-dimensional $\mathrm{T} 2 * \mathrm{w}$ fast low angle shot (echo time $=25.0$ milliseconds $[\mathrm{ms}]$, repetition time $=1,820 \mathrm{~ms}$, spatial resolution $=0.5 \times 0.5 \times 2 \mathrm{~mm}^{3}$, supratentorial coverage, number of slices $=35)$ and supratentorial 3-dimensional gradient echo flow-compensated susceptibility weighted imaging (SWI) (echo time $=14 \mathrm{~ms}$, repetition time $=25 \mathrm{~ms}$, flip angle $=12^{\circ}$, spatial resolution $=0.5 \times 0.5 \times 1.0 \mathrm{~mm}^{3}$ ) yielding magnitude, SWI-filtered phase and reconstructed SWI images.

\begin{tabular}{|lll|}
\hline Table $1 \quad$ Demographic details & & \\
& NMOSD & RRMS \\
No. & 10 & 10 \\
Female, $n$ & 10 & $5^{\mathrm{a}}$ \\
Age, $y$, mean \pm SD & $47 \pm 12$ & $40 \pm 7^{\mathrm{b}}$ \\
Range & $30-69$ & $26-49$ \\
Disease duration, ${ }^{c} y$, mean \pm SD & $8 \pm 7$ & $6 \pm 4^{\mathrm{d}}$ \\
Range & $1-29$ & $0-12$ \\
EDSS score, median & 3.75 & $1.5^{\mathrm{e}}$ \\
Range & $1.5-6.0$ & $0-2.5$ \\
NMOSD, $\mathrm{n}$ & 10 & NA \\
NMO & 3 & NA \\
ON & 0 & NA \\
LETM & 7 & NA \\
\hline
\end{tabular}

Abbreviations: EDSS = Expanded Disability Status Scale; LETM = longitudinally extensive transverse myelitis; $\mathrm{NA}=$ not applicable; NMO = neuromyelitis optica; NMOSD = NMO spectrum disorder; ON = optic neuritis; RRMS $=$ relapsing remitting multiple sclerosis.

${ }^{a} p=0.010$, Pearson $\chi^{2}$ test to assess differences in sex between patients with NMOSD and RRMS.

${ }^{\mathrm{b}} \mathrm{p}=0.043$, Mann-Whitney $U$ test to assess differences in age between patients with NMOSD and RRMS.

${ }^{\mathrm{c}}$ Disease duration $=$ time since first symptoms.

${ }^{d} p=0.853$, Mann-Whitney $U$ test to assess differences in disease duration between patients with NMOSD and RRMS.

${ }^{e} p=0.001$, Student $t$ test to assess differences in the EDSS between patients with NMOSD and RRMS.
Image analysis. MRIs were analyzed by a trained investigator (S.S.) blinded to clinical details (diagnosis, Expanded Disability Status Scale score, age, sex) using the OsiriX software package (version 3.8.1; OsiriX Foundation, Geneva, Switzerland). First, all hyperintense brain lesions larger than $3 \mathrm{~mm}$ in diameter were marked on T2* w images. The 3 -mm cutoff was used to ensure an optimal characterization of the lesion morphology. T2* ${ }^{\mathrm{w}}$ lesions outside of the field of view of SWI-phase images were excluded from further analyses.

Next, each existent $\mathrm{T} 2 * \mathrm{w}$ lesion was marked on phase images in a side-by-side analysis.

Hereby, the existence of phase changes in or around brain lesions was noted and grouped into 4 categories: (1) lesions with paramagnetic (positive) phase changes in the center of the lesions that are nodular in appearance, (2) lesions with paramagnetic (positive) phase changes at the edge of the lesions that are rimlike in appearance, (3) lesions without any intralesional phase changes, and (4) other lesions with intralesional phase changes not meeting these criteria. The latter were termed "lesions with unspecific phase changes" (figure). Since our scanner uses a lefthanded system, a paramagnetic (positive) phase shift corresponds to a hyperintense or "bright" area on phase images. Phase changes that were clearly related to a blood vessel were excluded.

In addition, a lesion with a central vessel within the inner third of the lesion on axial $\mathrm{T} 2 * \mathrm{w}$ images was classified as a perivascular lesion by an expert reader regarding the 3 -dimensional shape of the lesion and the vessels.

Statistical analysis and interrater reliability. All analyses were performed using IBM SPSS Statistics (version 20; IBM, Armonk, NY). The $p$ values $<0.05$ were considered significant. Because of the exploratory nature of the study, no adjustments for multiple comparisons were made. Group differences in age, disease duration, existence of a central vein, and intralesional phase changes between NMOSD and MS were assessed using a nonparametric Mann-Whitney $U$ test. Pearson $\chi^{2}$ was used to assess sex differences, and Student $t$-test was used to investigate group differences in the Expanded Disability Status Scale. In addition, 10 randomly selected patients with MS or NMOSD were reanalyzed by a second blinded investigator (K.M.) to assess interrater reliability. For this reason, intraclass correlation (ICC) was calculated as a 2-way mixed test of average measures using the consistency model.

RESULTS In total, we detected 112 brain lesions in patients with NMOSD, and 232 brain lesions were visualized in patients with MS on supratentorial $\mathrm{T} 2 * \mathrm{w}$ images.

Next, rim-like or nodular paramagnetic (positive) intralesional phase changes were analyzed (figure). In MS, 32 of 232 lesions (14\%) in 7 of 10 patients were characterized by a nodular paramagnetic (positive) phase shift and thus appeared "hyperintense" on magnetic resonance (MR) phase images corresponding to a hypointense signal on $\mathrm{T}^{*}{ }^{\mathrm{w}}$ and/or SWIs (lesion category I; figure, A).

Furthermore, a distinct rim-like paramagnetic (positive) phase shift was visible in 75 of 232 MS lesions (32\%) in all but one patient with MS (lesion category II; figure, B).

Contrarily, the vast majority of NMOSD lesions were neither characterized by nodular ( 2 of 112 lesions, $2 \%, p<0.001)$ nor rim-like intralesional phase changes ( 2 of 112 lesions, $2 \%, p<0.001$; table 2 ). 


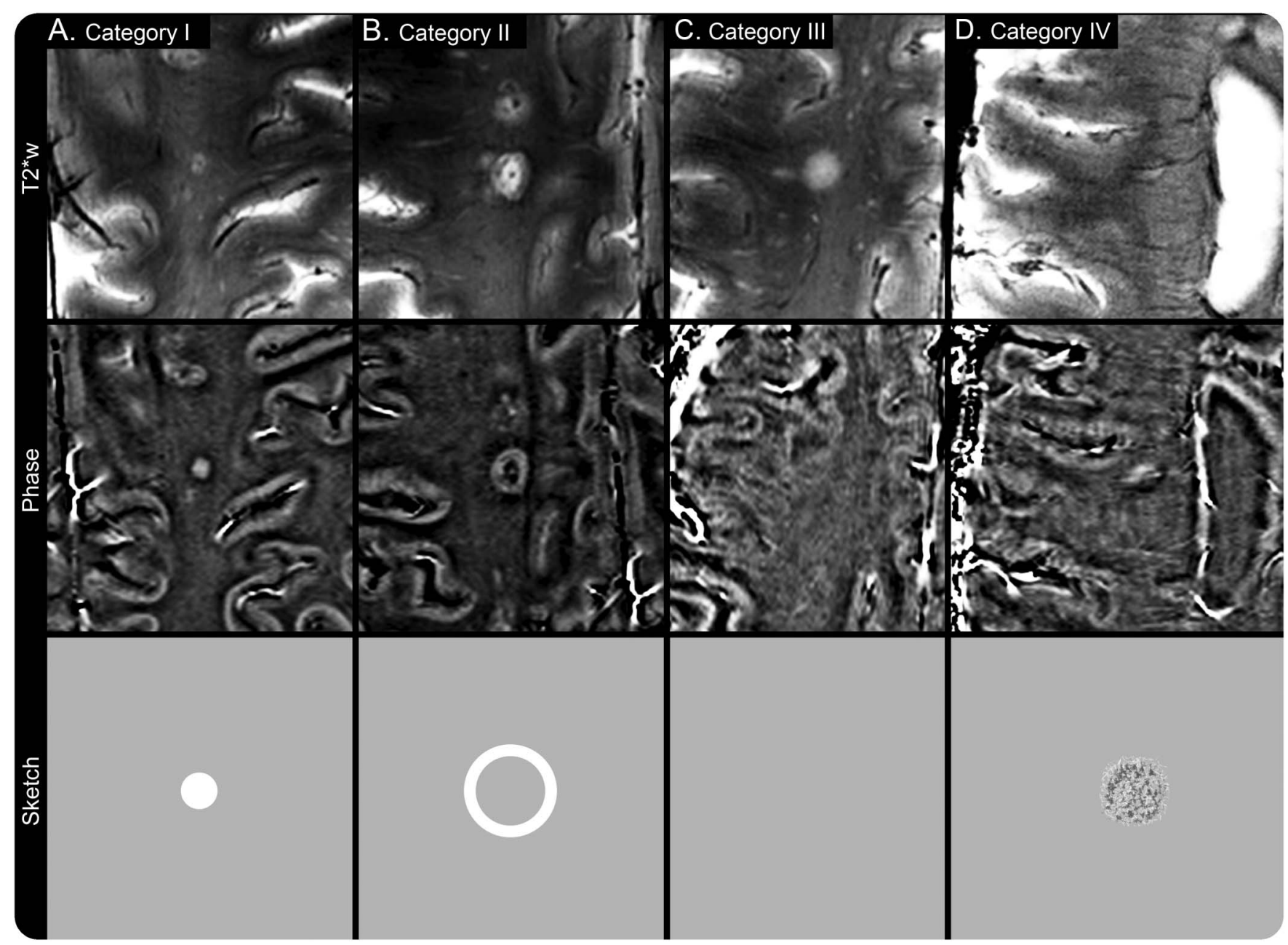

In this study, the existence of phase changes in or around brain lesions was noted and grouped into 4 categories. The figure shows examples of MS (A, B, D) and NMOSD (C) lesions imaged using T2*w and phase MRI. In the bottom row, a schematic is presented for each type of lesion illustrating ideal theoretic phase image appearance. Briefly, category I lesions (A) are characterized by paramagnetic (positive) phase changes in the center of the lesions that are nodular in appearance. Category II lesions (B) show paramagnetic (positive) phase changes at the edge of the lesions that are rim-like in appearance, and category III lesions (C) do not exhibit any intralesional phase changes. Finally, lesions with intralesional phase changes not meeting these criteria are category IV lesions (D). In this example (D), the MS lesion appears to have a small T2*w hypointense rim, but the corresponding phase changes are inconclusive and were thus categorized into lesion category IV. In addition, note the existence of a central vein in the center of the MS lesions (A, B, D) and the absence of such a vessel in the neuromyelitis optica lesion $(C)$. MS = multiple sclerosis; NMOSD = neuromyelitis optica spectrum disorder; $T 2 * \mathrm{w}=\mathrm{T} 2 *$-weighted.

A significant proportion of lesions in patients with NMOSD (107 of 112 lesions, 96\%) or MS (116 of 232 lesions, 50\%) did not show any MRI phase changes (lesion category III; figure, C), and a total number of $9 \mathrm{MS}$ and 1 NMOSD lesions presented with rather unspecific MRI phase changes (lesion category IV; figure, D).

In addition, the existence of an intralesional central vein was analyzed on $\mathrm{T} 2 * \mathrm{w}$ images. As reported previously, ${ }^{3,4}$ a central vein was typically visible in the inner third of MS lesions (193 of 232 lesions, 83\%) but only rarely existent in NMOSD lesions (28 of 112 lesions, $25 \%, p<0.001$ ). The morphology of NMOSD and MS lesions is detailed in table 2.

Interrater reliability. Interrater reliability was assessed in a subgroup of 10 randomly selected patients. ICC was $>0.8$ for lesion count $(\mathrm{ICC}=0.90)$, the number of lesions with a central vein (ICC $=0.95)$, and the number of lesions with rim-like (ICC $=0.96$ ) or nodular (ICC $=0.84$ ) phase changes indicating good interrater reliability of these parameters.

DISCUSSION In this study, we compared the morphology of NMOSD vs MS lesions on high spatial resolution SWI-filtered phase images and observed distinct lesion characteristics that were nearly exclusively found in MS but not in NMOSD lesions. Thus, this work adds to the ongoing discussion ${ }^{5}$ on the diagnostic value of phase white matter signal abnormalities in differentiating MS from other diseases.

In MS, the source of the phase contrast in or around lesions remains speculative, but iron-rich 
Table 2 Lesion morphology on gradient echo images

\begin{tabular}{|c|c|c|c|c|c|c|}
\hline & Lesion count ${ }^{a}$ & $\begin{array}{l}\text { Lesions with } \\
\text { nodular positive } \\
\text { phase changes }\end{array}$ & $\begin{array}{l}\text { Lesions with } \\
\text { rim-like positive } \\
\text { phase changes }\end{array}$ & $\begin{array}{l}\text { Lesions without } \\
\text { phase alterations }\end{array}$ & $\begin{array}{l}\text { Lesions with } \\
\text { unspecific phase } \\
\text { alterations }\end{array}$ & $\begin{array}{l}\text { Perivascular }{ }^{\text {b }} \\
\text { lesions }\end{array}$ \\
\hline \multicolumn{7}{|l|}{ NMOSD } \\
\hline No. & 112 & 2 & 2 & 107 & 1 & 28 \\
\hline Mean \pm SD & $11 \pm 13$ & $0.2 \pm 0.4$ & $0.2 \pm 0.4$ & $11 \pm 13$ & $0.1 \pm 0.3$ & $3 \pm 4$ \\
\hline Range & $1-35$ & $0-1$ & $0-1$ & $1-35$ & $0-1$ & $0-11$ \\
\hline \multicolumn{7}{|l|}{ RRMS } \\
\hline No. & 232 & 32 & 75 & 116 & 9 & 193 \\
\hline Mean \pm SD & $23 \pm 15$ & $3 \pm 3$ & $8 \pm 10$ & $12 \pm 12$ & $1 \pm 2$ & $19 \pm 13$ \\
\hline Range & $2-50$ & $0-8$ & $0-33$ & $0-40$ & $0-6$ & $2-41$ \\
\hline$p$ & 0.063 & 0.015 & $<0.001$ & 0.481 & 0.247 & $<0.001$ \\
\hline
\end{tabular}

Abbreviations: NMOSD = neuromyelitis optica spectrum disorder; RRMS = relapsing remitting multiple sclerosis.

${ }^{\text {a }}$ Lesion count $=$ total number of lesions detectable on $\mathrm{T} 2 *$-weighted images.

${ }^{\mathrm{b}}$ Perivascular $=$ visibility of a small central vein within the lesion center.

macrophages or microglia, ${ }^{7}$ solutes, proteins, antibodies, cytokines, and immune cells have been hypothesized to cause rim-like phase changes around MS lesions. ${ }^{8}$

Nodular phase changes - a feature of another proportion of MS lesions as reported previously ${ }^{9}$-were discussed to be caused by iron deposits as a consequence of, e.g., dying iron-rich oligodendrocytes, ${ }^{10}$ perivascular hemoglobin leakage, ${ }^{11}$ or a loss of diamagnetic myelin. ${ }^{12}$

In NMOSD, such nodular or rim-like paramagnetic phase changes were virtually absent. These differences may represent variant patterns of lesion evolution or iron metabolism between MS and NMOSD.${ }^{13}$ In MS, evidence has emerged that brain iron metabolism is altered since iron accumulates, e.g., in the basal ganglia. ${ }^{14}$ In alignment with a previous study that failed to identify abnormal iron deposits in the basal ganglia of patients with NMOSD,${ }^{15}$ our data suggest that NMOSD is not associated with alteration in brain iron metabolism, but histopathologic confirmation is needed.

Some limitations of this study of a small sample size need to be addressed. The NMOSD group was older than the MS group, which may have influenced our results since the magnetic susceptibility of (MS) brain lesions decreases with aging of the lesion. ${ }^{16}$ Most important, lesions within the brainstem, spinal cord, and optic nerves could not be analyzed, and brain lesions typical for $\mathrm{NMOSD}^{17}$ were not present in our NMOSD cohort. Thus, the existence of any MRI phase changes in these lesions remains unknown. From a technical point of view, signal inhomogeneities were present on $7 \mathrm{~T} \mathrm{~T} 2{ }^{*} \mathrm{w}$ images, and automated procedures to determine the total lesion volume were thus not performed. Finally, we cannot exclude that differences in lesion count or volume between the subgroups may have influenced our results.

In conclusion, paramagnetic intralesional phase changes were virtually absent in NMOSD but frequently detectable in MS. Future work should address the question of whether these imaging findings in or around lesions can indeed be used as a biomarker to better distinguish MS from NMOSD.

\section{AUTHOR CONTRIBUTIONS}

T.S., P.D., L.H., K.R., T.N., I.K., F. Paul, Y.G., and J.W.: study concept and design. T.S., F. Pache, P.D., P.N., and J.W.: acquisition of data. T.S., S.S., and K.M.: analysis. T.S., S.S., K.M., F. Pache, P.D., L.H., K.R., P.N., S.C., T.N., I.K., F. Paul, Y.G., and J.W.: interpretation. T.S., S.S., K.M., F. Pache, P.D., L.H., K.R., P.N., S.C., T.N., I.K., F. Paul, Y.G., and J.W.: critical revision of the manuscript for important intellectual content. T.S., L.H., K.R., T.N., I.K., F. Paul, Y.G., and J.W.: study supervision.

\section{ACKNOWLEDGMENT}

This work was supported by the Guthy-Jackson Charitable Foundation, the German Research Foundation (DFG Exc 257 to F.P.), and the German Ministry for Education and Research (Competence Network Multiple Sclerosis) to F.P. and K.R. Our technicians and study nurses Antje Els, Susan Pikol, Cynthia Kraut, and Gritt Stoffels gave invaluable support.

\section{STUDY FUNDING}

This work was supported by the Guthy-Jackson Charitable Foundation, the German Research Foundation (DFG Exc 257), and the Competence Network Multiple Sclerosis.

\section{DISCLOSURE}

T. Sinnecker received travel funding from Bayer, Teva, Novartis, Genzyme. S. Schumacher and K. Mueller report no disclosures. F. Pache received travel funding from Genzyme, Bayer, Biogen Idec, ECTRIMS, received research support from Charite-Universitaetsmedizin Berlin, Berlin Institute of Health, KKNMS-Bundesministerium für Bildung und Forschung, Novartis. P. Dusek received research support from the Ministry of Health of the Czech Republic. L. Harms served on the scientific advisory boards for Novartis, Sanofi/Genzyme, Roche, Biogen, received travel funding and/or speaker honoraria from Novartis, Biogen Idec, Merck Serono, Bayer HealthCare, Grifols, Teva. K. Ruprecht served on the scientific advisory board for Sanofi-Aventis/Genzyme, Novartis, 
Roche, received travel funding and/or speaker honoraria from Bayer HealthCare, Biogen Idec, Merck Serono, Sanofi-Aventis/Genzyme, Teva Pharmaceuticals, Novartis, Guthy Jackson Charitable Foundation, is an associate editor for PLoS One, received publishing royalties from Elsevier, received research support from Novartis, German Ministry of Education and Research. P. Neytrova and S. Chawla report no disclosures. T. Niendorf received travel funding from Siemens Healthcare, Erlangen Germany, was a guest editor for Magnetic Resonance Materials in Physics, Biology and Medicine, is the founder and CEO of MRI.TOOLS GmbH, received research support from Siemens Healthcare, Erlangen Germany, Helmholtz Association. I. Kister served on the advisory board for Biogen Idec, consulted for Biogen Idec, received research support from Biogen Idec, Serono, Novartis, Guthy-Jackson Charitable Foundation, Nationa Multiple Sclerosis Society. F. Paul served on the scientific advisory board for Novartis, MedImmune, received travel funding and/or speaker honoraria from Bayer, Novartis, Biogen Idec, Teva, Sanofi-Aventis/Genzyme, Merck Serono, Alexion, Chugai, MedImmune, Shire, is an academic editor for PLoS One, is an associate editor for Neurology ${ }^{\circledR}$ Neuroimmunology \& Neuroinflammation, has consulted for Sanofi/Genzyme, Biogen Idec, MedImmune, Shire, Alexion, received research support from Bayer, Novartis, Biogen Idec, Teva, Sanofi-Aventis/Genzyme, Alexion, Merck Serono, German Research Council, Werth Stiftung of the City of Cologne, German Ministry of Education and Research, Arthur Arnstein Stiftung Berlin, Arthur Arnstein Foundation Berlin, Guthy-Jackson Charitable Foundation, National Multiple Sclerosis Society of the United States. Y. Ge received research support from NIH, National MS Society. J. Wuerfel served on the advisory boards for Novartis, Biogen, Genzyme, received travel support from Novartis, and speaker honoraria from Bayer, Biogen Idec, Novartis, is the CEO of MIAC AG, received research support from the German Ministry of Education and Research, German Ministry of Economy, University Medicine Goettingen. Go to Neurology.org/nn for full disclosure forms.

Received January 2, 2016. Accepted in final form May 31, 2016.

\section{REFERENCES}

1. Jarius $S$, Ruprecht $\mathrm{K}$, Wildemann B, et al. Contrasting disease patterns in seropositive and seronegative neuromyelitis optica: a multicentre study of 175 patients. J Neuroinflammation 2012;9:14.

2. Wingerchuk DM, Banwell B, Bennett JL, et al. International consensus diagnostic criteria for neuromyelitis optica spectrum disorders. Neurology 2015;85:177-189.

3. Sinnecker T, Dörr J, Pfueller CF, et al. Distinct lesion morphology at 7-T MRI differentiates neuromyelitis optica from multiple sclerosis. Neurology 2012;79:708-714.

4. Kister I, Herbert J, Zhou Y, Ge Y. Ultrahigh-field MR (7 T) imaging of brain lesions in neuromyelitis optica. Mult Scler Int 2013;2013:398259.
5. Hagemeier J, Heininen-Brown M, Gabelic T, et al. Phase white matter signal abnormalities in patients with clinically isolated syndrome and other neurologic disorders. AJNR Am J Neuroradiol 2014;35:1916-1923.

6. Polman $\mathrm{CH}$, Reingold SC, Banwell B, et al. Diagnostic criteria for multiple sclerosis: 2010 revisions to the McDonald criteria. Ann Neurol 2011;69:292-302.

7. Pitt D, Boster A, Pei W, et al. Imaging cortical lesions in multiple sclerosis with ultra-high-field magnetic resonance imaging. Arch Neurol 2010;67:812-818.

8. Absinta M, Sati P, Gaitán MI, et al. Seven-tesla phase imaging of acute multiple sclerosis lesions: a new window into the inflammatory process. Ann Neurol 2013;74:669678.

9. Bian W, Harter K, Hammond-Rosenbluth KE, et al. A serial in vivo $7 \mathrm{~T}$ magnetic resonance phase imaging study of white matter lesions in multiple sclerosis. Mult Scler 2013;19:69-75.

10. Hametner S, Wimmer I, Haider L, Pfeifenbring S, Brück W, Lassmann $\mathrm{H}$. Iron and neurodegeneration in the multiple sclerosis brain. Ann Neurol 2013;74:848-861.

11. Bagnato F, Hametner S, Yao B, et al. Tracking iron in multiple sclerosis: a combined imaging and histopathological study at 7 tesla. Brain 2011;134(pt 12):36023615.

12. Li W, Wu B, Liu C. Quantitative susceptibility mapping of human brain reflects spatial variation in tissue composition. Neuroimage 2011;55:1645-1656.

13. Brück W, Popescu B, Lucchinetti CF, et al. Neuromyelitis optica lesions may inform multiple sclerosis heterogeneity debate. Ann Neurol 2012;72:385-394.

14. Habib CA, Liu M, Bawany N, et al. Assessing abnormal iron content in the deep gray matter of patients with multiple sclerosis versus healthy controls. AJNR Am J Neuroradiol 2012;33:252-258.

15. Chen X, Zeng C, Luo T, et al. Iron deposition of the deep grey matter in patients with multiple sclerosis and neuromyelitis optica: a control quantitative study by $3 \mathrm{D}-$ enhanced susceptibility-weighted angiography (ESWAN). Eur J Radiol 2012;81:e633-e639.

16. Chen W, Gauthier SA, Gupta A, et al. Quantitative susceptibility mapping of multiple sclerosis lesions at various ages. Radiology 2014;271:183-192.

17. Kim HJ, Paul F, Lana-Peixoto MA, et al. MRI characteristics of neuromyelitis optica spectrum disorder: an international update. Neurology 2015;84:1165-1173. 


\section{Neurology \\ Neuroimmunology \& Neuroinflammation}

MRI phase changes in multiple sclerosis vs neuromyelitis optica lesions at 7T

Tim Sinnecker, Sophie Schumacher, Katharina Mueller, et al.

Neurol Neuroimmunol Neuroinflamm 2016;3;

DOI 10.1212/NXI.0000000000000259

This information is current as of July 22, 2016

\section{Updated Information \& Services}

References

Citations

Subspecialty Collections

Permissions \& Licensing

Reprints including high resolution figures, can be found at: http://nn.neurology.org/content/3/4/e259.full.html

This article cites 17 articles, 2 of which you can access for free at: http://nn.neurology.org/content/3/4/e259.full.html\#\#ref-list-1

This article has been cited by 2 HighWire-hosted articles: http://nn.neurology.org/content/3/4/e259.full.html\#\#otherarticles

This article, along with others on similar topics, appears in the following collection(s):

Autoimmune diseases

http://nn.neurology.org//cgi/collection/autoimmune_diseases Devic's syndrome

http://nn.neurology.org//cgi/collection/devics_syndrome MRI

http://nn.neurology.org//cgi/collection/mri

Multiple sclerosis

http://nn.neurology.org//cgi/collection/multiple_sclerosis

Information about reproducing this article in parts (figures,tables) or in its entirety can be found online at:

http://nn.neurology.org/misc/about.xhtml\#permissions

Information about ordering reprints can be found online: http://nn.neurology.org/misc/addir.xhtml\#reprintsus

Neurol Neuroimmunol Neuroinflamm is an official journal of the American Academy of Neurology.

Published since April 2014, it is an open-access, online-only, continuous publication journal. Copyright $(\odot$ 2016 American Academy of Neurology. All rights reserved. Online ISSN: 2332-7812.

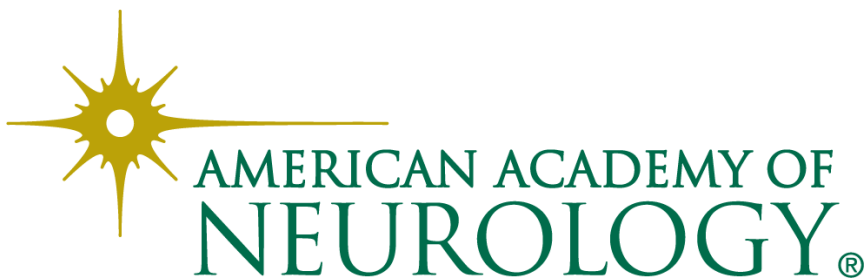

